\title{
Antioxidant isolated from Schisandra propinqua (Wall.) Baill
}

\author{
FENG HUANG ${ }^{\mathrm{A}}$, LIJIA XU⿱B⿵冂⿰丨丨 ${ }^{\mathrm{B}}$ and GANGGANG SHI*, A
}

\author{
${ }^{a}$ Medical College of Shantou University, Guangdong, China, 515031 \\ ${ }^{\mathrm{b}}$ Institute of Medicinal Plant Development, Chinese Academy of Medical Sciences \& Peking Union Medical \\ College, Beijing, China, 100094
}

\begin{abstract}
Schisandra propinqua (Wall.) Baill.(Schisandraceae) is widely used as a Chinese folk medicine. In this study, activity-guided fractionation of the ethanol extract from the stem of Schisandra propinqua led to the isolation of four extracts. Subsequently, a neolignan 4,4-di(4-hydroxy-3-methoxyphenly)-2,3-dimethylbutanol was isolated from the EtOAc part of the stem of Schisandra propinqua, the free radical scavenging activities of which were researched in vitro. The present work demonstrated that extracts and pure compound possessed scavenging activities to DPPH, superoxide anions and hydroxy radical, and could depress lipid peroxidation reaction induced by oxygen radical produced by the $\mathrm{Fe}^{2+} /$ cysteine system in vitro. This suggests that the traditional application of Schisandra propinqua in China may be related to its antioxidant activities, and the EtOAc part of the stems of Schisandra propinqua can be utilized as an effective source of antioxidants.
\end{abstract}

Key terms: antioxidant, free radical, lipid peroxidation; Schisandra propinqua.

\section{INTRODUCTION}

Free radicals or reactive oxygen species, which are produced in vivo from various biochemical reactions, are involved in pathogenesis of many diseases like atherosclerosis, cancer, inflammation, diabetes mellitus, and also in aging (1). Free radicals not only cause direct damage to DNA, but also exert indirect effects such as de-regulation of cell proliferation and apoptosis, stimulation of angiogenesis, and modification of gene/protein expressions and protein activities. Reactive oxygen species such as the superoxide anion and the hydroxy radical, as well as hydrogen peroxide, are important mediators of cellular injury via destruction of membranes or alteration of critical enzyme systems, being able to trigger cancer and inflammatory development and progression (2,3). Many medicinal plants contain chemical compounds, such as flavonoids and lignan that exhibit antioxidant properties. Rhizomes and stems of Schisandra propinqua (Wall.) Baill. (Schisandraceae) are traditionally applied in Chinese folk medicine, such as analgesia and anti-inflammatory herbal drug against fracture, stomachache, hepatitis, vasculitis and rheumatism, after topical or oral administration (4). It was reported that aqueous extract of Schisandra propinqua showed anti-lung cancer and leukemia P-388 activities in vivo and in vitro respectively (5). In the present study, the scavenging activities of the extracts and a lignan from Schisandra propinqua against hydroxy radical, superoxide anion, and peroxyl radical have been tested in different cell-free systems through different techniques. We hope that our work can provide evidence to assess the medicinal potential of Schisandra propinqua and thus support its folklore application.

\footnotetext{
* Corresponding Author: Name: Ganggang Shi; Address: Medical College of Shantou University, Guangdong, China, 515031; E-mail:ggshi@stu.edu.cn; Tel: 86-0754-8900432
} 
MATERIALS AND METHODS

\section{Animals}

Male Wistar rats (180-220g) were obtained from the Animal Institute of the Chinese Academy of Medical Sciences, and housed in a standard animal facility environment with a food and water supply. The animal quarters were strictly maintained at $20-24^{\circ} \mathrm{C}$ and $50 \%$ relative humidity and followed a $12 \mathrm{~h} / 12 \mathrm{~h}$ light/dark cycle.

\section{Chemicals}

Thiobarbituric acid (TBA), sodium dodecyl sulfate (SDS), Vitamin C (Vc), 1,1diphenyl-2-picrylhydrazyl (DPPH), reduced beta-nicotinamide adenine dinucleotide (NADH), luminol and bovine serum albumin (BSA) were obtained from the Sigma Chemical Company. Cysteine, ferrous sulfate, phenazine methosulfate (PMS), hydrogen peroxide, copper sulfate, Foline-phenol, 1,10-phenathroline, trichloroacetic acid and other chemicals were purchased from the Beijing Chemical Company. Salvianolic acid A (SalA) was kindly provided by Prof. Lianniang Li of the Institute of Material Medica, Chinese Academy of Medical Sciences. All the chemicals used were of analytical grade.

\section{Plant materials}

The stems of Schisandra propinqua were collected in Shennongjia district, Hubei Province, the People's Republic of China, in January in 2000, and were identified by Prof. Ceming Tan of the Institute of Jiujiang Forest Plants, Hubei Province, the People's Republic of China. A voucher specimen has been deposited in the Herbarium of the institute.

\section{Extraction and isolation}

The isolation procedure was carried out as follows. Briefly, the dried stems of Schisandra propinqua $(2 \mathrm{~kg}$ ) were chopped into small pieces and extracted with $90 \%$ $\mathrm{EtOH}$ under reflux for three times $(2 \mathrm{~h} \times 3)$. The solvent was evaporated under vacuum to obtain the total extract SP (130 g). This residue was suspended in water and subsequently extracted by Petroleum Ether, EtOAc and $\mathrm{CHCl}_{3}$. The extracts obtained by different solvents were evaporated under vacuum to provide residue and identified as SPP (15 g), SPE (26 g), and SPC (29 g), respectively.

Extract SPE was chromatographed on a silica gel column (100-200 mesh) and eluted by petroleum ether/acetone gradient solvent (100: 0-50: 50). The fraction eluted with petroleum ether/acetone (80: 20) was further separated by silica gel-H CC with acetone/EtOAc (80: 20) as a solvent system to give compound $\mathbf{1}$ (98 $\mathrm{mg}$ ). The structure of the compound has been elucidated base on UV, MS, and NMR spectra methods.

\section{DPPH scavenging assay}

1,1-diphenyl-2-picrylhydrazyl (DPPH) is a fatty free radical, stable at room temperature, which produces a violet solution in ethanol. In the presence of antioxidant compounds, DPPH is reduced, producing a colorless ethanol solution. The free radical scavenging activities of four extracts and compound $\mathbf{1}$ from Schisandra propinqua were evaluated with DPPH. Vitamin $\mathrm{C}(\mathrm{Vc})$ and Salvianolic acid A (SalA) (6) were used as positive reference free radical scavengers. Ten $\mu \mathrm{l}$ of the distilled water solution containing different amounts of the extracts, compound $\mathbf{1}$ or positive references, were added into $190 \mu \mathrm{l}$ of freshly prepared DPPH solution $\left(6.5 \times 10^{-}\right.$ $5 \mathrm{~mol} / \mathrm{L}$, in ethanol). An equal volume of vehicle was added into a blank control well. Absorbance at $517 \mathrm{~nm}$ was measured on a Zenyth200 UV-Vis spectrophotometer (Anthos Co. Austria) 30 minutes after starting the reaction (7). All experiments were carried out four times and the mean effective scavenging concentrations $\left(\mathrm{SC}_{50}\right)$ were calculated.

\section{Superoxide anion scavenging assay}

The superoxide anions generated in the nonenzymatic system PMS/NADH (8). The superoxide anion free radical was measured using a luminol chemiluminescence system 
under the optimum luminance conditions of $\mathrm{pH}$ 8.91. The production and measurement of superoxide anions were performed according to procedures described in the references (9), with slight modification: 10 $\mu \mathrm{mol} / \mathrm{L}$ PMS was added into the reaction mixture containing $78 \mu \mathrm{mol} / \mathrm{L}$ NADH, 100 $\mu \mathrm{mol} / \mathrm{L}$ luminol, compound $\mathbf{1}$ and borax $/ \mathrm{HCl}$ buffer $(0.05 \mathrm{~mol} / \mathrm{L}, \mathrm{pH} 8.91)$ to initiate the reaction. The chemiluminescence intensity (count per second, CPS) was immediately measured on Topcount microplate scintillation and luminescence counter (USA) for twenty cycles. Values are presented as mean \pm standard deviation of six determinations.

\section{Hydroxy radical scavenging assay}

The method for formation of hydroxy radical by $\mathrm{CuSO}_{4}$-Phen- $\mathrm{V}_{\mathrm{C}}-\mathrm{H}_{2} \mathrm{O}_{2}$ was carried out according to procedures described in references $(10,11)$ with slight modification. $0.02 \mathrm{~mol} / \mathrm{L} \mathrm{H}_{2} \mathrm{O}_{2}$ was added to reaction mixture containing $100 \mu \mathrm{mol} / \mathrm{L} \quad 1,10$ phenathroline, $50 \mu \mathrm{mol} / \mathrm{L} \mathrm{CuSO}_{4}, 100 \mu \mathrm{mol} /$ $\mathrm{L} \mathrm{Vc}$, compound investigated and borat/ boric acid buffer $(\mathrm{pH} 8.98)$ to initiate the reaction except for the blank control well. The chemiluminescence intensity (CPS) was immediately measured on a Topcount microplate scintillation and luminescence counter. Each well was detected for three seconds, and each plate was measured for twenty cycles. A chemiluminescence kinetic curve was obtained. The scavenging percentage to hydroxy radical was calculated by comparing peak value of chemiluminescence intensity. Results are presented as mean \pm standard deviation of four determinations.

\section{Lipid peroxidation assay}

In the mode of formation of microsomal lipid peroxidation induced by iron/cysteine and the principle of TBA reaction, a simple one-step microassay for the studying and screening of antioxidants in 96-well plate was used (12). Male Wistar rats were fasted for 24 hours. After homogenization and centrifugation, microsome fractions of the liver were suspended in TMS buffer. The content of protein was determined by the method of Lowry. The microsomal suspension from rat liver $(7.5 \mathrm{~g} / \mathrm{L})$ was used for this experiment. After incubation of the reaction system at $37^{\circ} \mathrm{C}$ for 30 minutes, the content of malondialdehyde(MDA) from lipid peroxidation was measured. At the end of incubation, TBA reagent $(0.67 \%$ TBA, $10 \%$ TCA, 5\% SDS) was added into the reaction mixture, and reacted with $\mathrm{MDA}$ for 30 minuets at $60^{\circ} \mathrm{C}$. The absorbance of TBA reaction product was measured at $540 \mathrm{~nm}$ on Zenyth200 UV-Vis spectrophotometer. Each determination was repeated four times.

\section{RESULTS}

\section{Structure of compound 1}

The structure of compound $\mathbf{1}$ has been elucidated base on UV, MS, and NMR spectra methods. Yellow gum; $\mathrm{UV}(\mathrm{EtOH}) \lambda_{\max }(\log \varepsilon)$ : 206(4.27), 245(sh2.99), 282(sh3.12); molecular weight: 346.178; molecular formula: $\mathrm{C}_{20} \mathrm{H}_{26} \mathrm{O}_{5} \cdot{ }^{1} \mathrm{H}-\mathrm{NMR}(\mathrm{CDCl} 3,400 \mathrm{MHz}): \delta$ $6.88\left(1 \mathrm{H}, \mathrm{d}, \mathrm{J}=1.6 \mathrm{~Hz}, \mathrm{H}-2{ }^{\prime}\right), 6.71(1 \mathrm{H}, \mathrm{d}$, $\mathrm{J}=1.6 \mathrm{~Hz}, \mathrm{H}-5^{\prime}$ '), 6.80(1H, dd, J=1.6/8.0 Hz, H-6'), 3.69, 3.22(1H, each, H-7), 1.79(1H, $\mathrm{m}, \mathrm{H}-8), 0.99(3 \mathrm{H}, \mathrm{d}, \mathrm{J}=6.4 \mathrm{~Hz}, \mathrm{H}-9)$, 6.84(1H, d, J=1.6 Hz, H-2'), 6.68(1H, d, $\mathrm{J}=1.6 \mathrm{~Hz}, \mathrm{H}-5$ ' $), 6.74(1 \mathrm{H}, \mathrm{dd}, \mathrm{J}=1.6 / 8.0 \mathrm{~Hz}$, H-6' $), 3.65\left(1 \mathrm{H}, \mathrm{m}, \mathrm{H}-7^{\prime}\right), 2.33(1 \mathrm{H}, \mathrm{m}, \mathrm{H}-$ $\left.8^{\prime}\right), 0.84\left(3 \mathrm{H}, \mathrm{d}, \mathrm{J}=7.2 \mathrm{~Hz}, \mathrm{H}-9\right.$ '); ${ }^{13} \mathrm{C}-$ NMR(CDCl3, 100MHz): $\delta$ 137.35(C-1), 111.62(C-2), 147.51(C-3), 143.77(C-4), 114.84(C-5), 119.97(C-6,6 2), 63.04(C-7), 40.65(C-8), 15.64(C-9), $136.86\left(\mathrm{C}-1^{\prime}\right)$, 111.35(C-2'), 147.41(C-3'), 143.68(C-4'), 114.69(C-5'), 55.78(C-7'), 36.08(C-8'), 12.34(C-9'), 55.78(3-OMe), 55.09(3'$\mathrm{OMe})$. Compound 1 was identified as 4,4di (4-hydroxy-3-methoxy phenly)-2,3dimethylbutanol (13), as shown in Figure 1.

\section{DPPH scavenging activity}

As to the bleaching of the DPPH, this test is carried out in ethanol solution and thus is useful to determine the free radical scavenging effect of the extracts and compound from Schisandra propinqua. All 


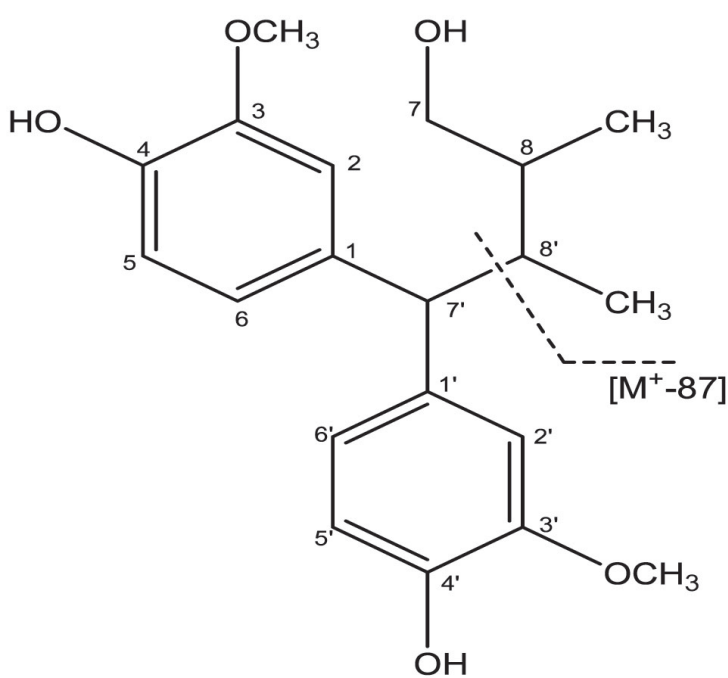

Figure 1: The structure of 4,4-di(4-hydroxy-3methoxyphenly)-2,3-dimethylbutanol

extracts and the lignan elicited a significant free radical scavenging effect at 30 minutes, and the effects were concentrationdependent. The scavenging effect of extract SPE on DPPH was significantly stronger than that of extracts SPP and SPC (Table 1). The $\mathrm{SC}_{50}$ of compound 1 was $2.19 \mu \mathrm{M}$ (Table 2). The free radical scavenging effect of compound 1 was comparable with that of SalA ( SD $_{50} 4.45 \mu \mathrm{M}$, Table 2).

\section{Superoxide anions scavenging activity}

We investigated the in vitro superoxide anion scavenging activities of the compound from Schisandra propinqua. The influence of the compound on chemiluminescence kinetics was observed. The $\mathrm{IC}_{50}$ value of compound $\mathbf{1}$ was 1.18 $\mu \mathrm{M}$. The result showed that it was the superoxide anion free radical scavenger, and the effect was as potent as the reference antioxidant, Salvianolic acid A, which is a water-soluble active component of Salvia miltiorrhiza (Table 2).

TABLE 1

Scavenging DPPH activity of extracts

\begin{tabular}{lcc}
\hline extracts & \multicolumn{2}{c}{ DPPH decoloration (\%) } \\
\cline { 2 - 3 } & $20 \mu \mathrm{g} / \mathrm{ml}$ & $100 \mu \mathrm{g} / \mathrm{ml}$ \\
\hline SP & $38.79 \pm 3.38$ & $88.54 \pm 3.72$ \\
SPP & $10.58 \pm 0.80$ & $22.08 \pm 4.44$ \\
SPE & $29.74 \pm 3.10^{*} \#$ & $84.40 \pm 5.60^{*}$ \# \\
SPC & $14.51 \pm 1.43$ & $48.61 \pm 5.33$ \\
\hline
\end{tabular}

Values are presented as mean \pm standard deviation. $(n=4) .{ }^{*}$ SPE vs SPP, $p<0.05 .{ }^{\#}$ SPE vs SPC, $p<0.05$.

\section{Hydroxy radical scavenging activity}

Hydroxy radical scavenging activities of the compound were measured in the system of $\mathrm{CuSO}_{4}$-Phen- $\mathrm{V}_{\mathrm{C}}-\mathrm{H}_{2} \mathrm{O}_{2}$ by the method of chemiluminescence. The result indicated that along with the increase of concentrations of the compound, the effect on scavenging hydroxy radical also gradually increased. The $\mathrm{IC}_{50}$ value of compound 1 was $1.59 \mu \mathrm{M}$. It was the effective hydroxy radical scavenger (Table 2).

TABLE 2

Scavenging free radical activities of compound $\mathbf{1}$

\begin{tabular}{lcccc}
\hline compound & $\begin{array}{c}\mathrm{DPPH} \mathrm{SC} \\
(\mathrm{n}=4)\end{array}$ & $\begin{array}{c}\text { superoxide anion } \\
\mathrm{IC}_{50}(\mu \mathrm{M})(\mathrm{n}=6)\end{array}$ & $\begin{array}{c}\text { hydroxy radical } \\
\mathrm{IC}_{50}(\mu \mathrm{M})(\mathrm{n}=4)\end{array}$ & $\begin{array}{c}\text { lipid peroxidation } \\
\mathrm{IC}_{50}(\mu \mathrm{M})(\mathrm{n}=4)\end{array}$ \\
\hline $\mathbf{1}$ & $2.19 \pm 0.12$ & $1.18 \pm 0.14$ & $1.59 \pm 0.09$ & $1.33 \pm 0.14$ \\
$\mathrm{Vc}$ & $127.45 \pm 0.62$ & - & - & - \\
$\mathrm{SalA}$ & $4.45 \pm 0.63$ & $0.44 \pm 0.02$ & $4.10 \pm 0.40$ & $2.51 \pm 0.14$ \\
\hline
\end{tabular}

Compound $\mathbf{1}$ is 4,4-di(4-hydroxy-3-methoxyphenly)-2,3-dimethylbutanol. Vc and SalA as references. Values are presented as mean \pm standard deviation. - , no data. 


\section{Lipid peroxidation inhibitory activity}

The protective effects of the compound from Schisandra propinqua on lipid peroxidations in microsome induced by oxygen radical produced by the $\mathrm{Fe}^{2+}$ / cysteine system were investigated. The rat liver microsome lipid peroxidation was significantly inhibited by the compound in a dose-response manner. The $\mathrm{IC}_{50}$ value of compound 1 was $1.33 \mu \mathrm{M}$, and the $\mathrm{IC}_{50}$ of SalA was $2.51 \mu \mathrm{M}$ (Table 2).

\section{DISCUSSION}

The superoxide anion, hydroxy radical, hydrogen peroxide and singlet oxygen are produced during the procedure of metabolism in the body, commonly named active oxygenderived species. The disorder of generation and scavenge of free radicals can cause serious injuries to the body. The significant increases in the concentrations of active oxygen species in the body damage protein and nucleic acid molecules, inactivate enzymes and cell membranes, which in turn leads to the development of various pathological states such as cancer and inflammation in the body (1-3). The possible blockade of these free-radical processes initiated by active oxygen species at the early stages is therefore particularly acute. So, it is advised to treat diseases induced by or associated with active oxygen-derived free radical via medicines with effects of free radical scavenging activities. Natural antioxidants have easy and unlimited access to metabolic processes in the body and produce virtually none of the side effects associated with synthetic agents. Thus, studies of medicinal plants as potential sources of antioxidants are of significant interest (14). In fact, some researchers have found that some natural compounds with scavenging free radical activities had advantages in procedures of cancer and inflammation (15-18). In our previous study, it was found that some lignan and triterpene contents isolated from Schisandra propinqua showed modest cytotoxic activity in vitro against the growth of various human tumor cell lines $(13,19)$. In the present study, we isolated four extracts and a lignan from stem of Schisandra propinqua, and investigated their antioxidant activities and free radical scavenging effects in different systems in vitro. We found their strong scavenging effects on active oxygen-derived free radicals and blocking lipid peroxidation processes, and found the scavenging effects of compound $\mathbf{1}$ on free radicals were as potent as that of SalA, a generally accepted antioxidant. Notably, the antioxidant components are chiefly located in EtOAc part of stem of Schisandra propinqua. Antioxidant activity of phenolic depends on the number and position of hydrogen-donating hydroxyl groups on the aromatic ring of the phenolic molecules (20). Thus, the good bioactivity of compound 1 maybe due to its phenolic structure and special skeleton, and its detailed action mechanism is still being investigated. In this study, we also isolated some other phenolic compounds, including protocatechuic acid (35 $\mathrm{mg})$, dihydroguaiaretic acid $(89 \mathrm{mg})$, gallic acid (42 mg) and quercimelin (29 mg), from EtOAc part of stem of Schisandra propinqua, and these polyphenolic compounds showed significantly free radical scavenging activities (data not show).

The results demonstrated that the components of Schisandra propinqua exerted strong antioxidant effects in vitro. It is suggested that the anticancer and antiinflammatory activities of Schisandra propinqua may be related to its scavenging effects on oxygen free radical, its inhibitory effect on lipid peroxidation, and may therefore be useful in prevention and treatment of diseases due to increased free radical production.

\section{ACKNOWLEGEMENTS}

We specially thank Prof. Ceming Tan for collaboration in the collection and identification of plant species. We also thank Prof. Lianniang Li for providing SalA.

\section{REFERENCES}

1. VALKO M, LEIBFRITZ D, MONCOL J, CRONIN MT, MAZUR M, TELSER J (2007) Free radicals and 
antioxidants in normal physiological functions and human disease. Int. J. Biochem. Cell Biol. 39: 44-84

2. GERONIKAKI AA, GAVALAS AM (2006) Antioxidants and inflammatory disease: synthetic and natural antioxidants with anti-inflammatory activity. Comb. Chem. High Throughput Screen 9: 425-42

3. HUSSAIN SP, HOFSETH LJ, HARRIS CC (2003) Radical causes of cancer. Nat. Rev. Cancer 3: 276-285

4. CHEN YG, QIN GW, XIE YY (2001) Dibenzocyclooctadiene lignans from Schisandra propinqua. Chem. J. Chinese Universities 22: 15181520

5. LIU JS, MA YT, HUANG MF (1988) Studies on the constituents of schisandraceae plants in Shennongjia district. Acta Chimica Sinica 46: 345-347

6. LI LN (1997) Water soluble active components of Salvia miltiorrhiza and related plants. J. Chinese Pharmaceutical Sci. 6: 57-64

7. BLOIS MS (1958) Antioxidant determinations by the use of a stable free radical. Nature 181: 1199-1200

8. PONTI V, DIANZANI MU, CHEESEMAN K, SLATER TF (1978) Studies on the reduction of nitroblue tetrazolium chloride mediated through the action of NADH and phenazine methosulphate. Chem. Biol. Interact. 23: 281-291

9. KANG JH, ZHANG YL (1997) Effects of oxaphenamidi on oxygen free radical and the oxidative hemolytic in erythrocytes. Modern Appl. Pharm. 14: 8-10

10. WHITEHEAD TP, THORPE GHG, MAXWELL SRJ (1992) Enhanced chemiluminescent assay for antioxidant capacity in biology fluids. Analytica Chimica Acta 266: 265-277

11. FAN XB, LI CJ, SHA DN, HU WL, HU TX (1998) The establishment of O-phenathroline chemiluminescent system for measuring $\mathrm{OH}$ radical. Basic Med. Sci. Clin. 18: 468-471

12. SUN SY, XU B, LI QJ, LI RZ (1995) One-step microassay for the measurement of anti-lipid peroxidation in 96-well plate. Progress Biochem. Biophys. 22: 165-169

13. XU LJ, HUANG F, CHEN SB, LI LN, CHEN SL, XIAO PG (2006) A cytotoxic neolignan from Schisandra propinqua (Wall.) Baill. J. Integr. Plant Biol. 48: 1493-97

14. URQUIAGA I, LEIGHTON F (2000) Plant polyphenol antioxidants and oxidative stress. Biol. Res. 33: 55-64

15. FREI B, HIGDON JV (2003) Antioxidant activity of tea polyphenols in vivo: evidence from animal studies. J. Nutr. 133: 3275S-3284S

16. LEE KW, LEE HJ (2006) The roles of polyphenols in cancer chemoprevention. Biofactors 26: 105-21

17. FERNANDEZ-PANCHON MS, VILLANO D, TRONCOSO AM, GARCIA-PARRILLA MC (2008) Antioxidant activity of phenolic compounds: from in vitro results to in vivo evidence. Crit. Rev. Food Sci. Nutr. 48: 649-71

18. DAS S, DAS DK (2007) Anti-inflammatory responses of resveratrol. Inflamm. Allergy Drug Targets 6: 16873

19. XU LJ, HUANG F, CHEN SB, ZHANG QX, LI LN, CHEN SL, XIAO PG (2006) New lignans and cytotoxic constituents from Schisandra propinqua. Planta Med. 72: 169-174

20. KIM DO, LEE CY (2004) Comprehensive study on vitamin $\mathrm{C}$ equivalent antioxidant capacity (VCEAC) of various polyphenolics in scavenging a free radical and its structural relationship. Crit. Rev. Food Sci. Nutr. 44: $253-73$. 